\title{
Maximum tolerable dose of red pepper decreases fat intake independently of spicy sensation in the mouth
}

\author{
Mayumi Yoshioka ${ }^{1,2 *}$, Makoto Imanaga ${ }^{2}$, Hiromi Ueyama ${ }^{2}$, Miya Yamane ${ }^{2}$, Yoshiko Kubo², \\ André Boivin ${ }^{1}$, Jonny St-Amand ${ }^{1}$, Hiroaki Tanaka ${ }^{2}$ and Akira Kiyonaga ${ }^{2}$ \\ ${ }^{1}$ Molecular Endocrinology and Oncology Research Center, Laval University Medical Center (CHUL) and \\ Department of Anatomy and Physiology, Laval University, 2705 Boulevard Laurier, Ste-Foy, Quebec G1V 4G2, \\ Canada \\ ${ }^{2}$ Faculty of Sport and Health Science, Fukuoka University, Fukuoka, 814-0184, Japan
}

(Received 18 August 2003 - Revised 16 February 2004 - Accepted 29 February 2004)

\begin{abstract}
Dietary red pepper suppresses energy intake and modifies macronutrient intake. We have investigated whether a stimulus in the mouth and the sensation of spiciness are necessary for red pepper-induced changes in energy and macronutrient intake in human volunteers. In a preliminary test, sixteen Japanese male volunteers tasted samples of a soup with graded doses of red pepper in order to define a moderate and a maximum tolerable (strong) dose of red pepper. On the day of the experiment, a standardised breakfast was given to the volunteers. At lunchtime, the subjects ingested one of four experimental soups containing either a placebo, a moderate or a strong dose of red pepper plus placebo capsules, or a placebo soup plus capsules delivering a strong dose of red pepper. The rest of the meal was given ad libitum to all subjects. The amount of food, protein and carbohydrate ingested was similar for all conditions. Energy and fat intake were similar after the ingestion of the moderate soup compared with placebo. However, the strong soup significantly lowered fat intake compared with placebo $(P=0.043)$, and ingestion of strong capsules also tended to suppress it $(P=0 \cdot 080)$. Moreover, energy intake after strong soup and capsules tended to be lower than placebo $(P=0.089$ and 0.076 , respectively). The present results indicate that the maximum tolerable dose is necessary to have a suppressive effect of red pepper on fat intake. The main site of the action of red pepper is not in the mouth.
\end{abstract}

Red pepper: Spiciness: Macronutrient intake

Obesity is an important cause of morbidity and is having an increasingly negative impact on healthcare systems in both industrialised and developing countries (Taubes, 1998; Wickelgren, 1998). Obesity can be simply described as the outcome of a positive energy balance characterised by an excess of energy intake over expenditure. Consequently, the prevention and treatment of obesity is possible through an increase in energy expenditure or a decrease in energy intake. Capsaicin, the pungent principal of red pepper, is known to enhance energy metabolism via a stimulation of the sympathoadrenal system (Watanabe et al. 1991). As a result, an ingestion of capsaicin decreases body-fat mass in a dose-dependent manner (Watanabe et al. 1991). The ingestion of red pepper stimulates the postprandial increase in RMR and the thermic effect of feeding (TEF), suppresses energy intake and modifies macronutrient intake (Yoshioka et al. 1999, 2001). Dietary fat is an important factor in the development of obesity because of its high energy density (Warwick \& Schiffman, 1992), its low potency to induce satiety (Lissner et al. 1987;
Kendall et al. 1991; Thomas et al. 1992) and its little contribution to the TEF (Flatt et al. 1985; Schutz et al. 1989; Bennett et al. 1992). These studies led to the proposal that capsaicin (red pepper) could be useful to treat obesity or prevent its development (Doucet \& Tremblay, 1997; Dulloo, 1998).

Diamond et al. (1985) have demonstrated that the TEF consists of a cephalic phase due to sensory stimulation (smell, taste and sight of food), controlled by the sympathetic nervous system (SNS), and a gastrointestinal phase associated with the digestion, absorption and storage of nutrients. In comparison with control animals with a similar food intake, weight gain is promoted by the blunting of the cephalic phase with stomach-tube feeding (Rothwell \& Stock, 1978). In our previous studies, the TEF was negatively correlated with subsequent energy intake $(r-0.512$, $P=0.0001$, unpublished conclusion drawn from the same subjects; Yoshioka et al. 1995, 1998, 1999). We have also reported that an ingestion of red pepper increases the cephalic phase of the TEF (Yoshioka et al. 1995,

\footnotetext{
Abbreviations: LF:HF, low frequency:high frequency ratio; MS+P, moderate soup plus placebo capsules; PS+P, placebo soup plus placebo capsules; $\mathrm{PS}+\mathrm{S}$, placebo soup plus strong capsules; SNS, sympathetic nervous system; SS+P, strong soup plus placebo capsules; TEF, thermic effect of feeding. * Corresponding author: Dr Mayumi Yoshioka, fax +1 418654 2761, email Mayumi.Yoshioka@crchul.ulaval.ca
} 
1998; Lim et al. 1997). These observations suggest that an ingestion of red pepper could contribute to the treatment of overweight and obesity by stimulating the cephalic phase of the TEF. Furthermore, the increase in SNS activity induced by red pepper is larger, and the dose required for the same effect is smaller, when it is ingested in a high concentration (appetiser) rather than in a low concentration (main dish) during a meal (Yoshioka et al. 1999). Because the effect of red pepper on energy metabolism and nutrient intake requires a transit in the mouth, we hypothesised that the effect involves a feeling of spiciness. In the present study, we investigated whether a stimulus in the mouth and the feeling of spiciness are necessary for red pepper-induced changes in energy and macronutrient intake in human subjects.

\section{Methods}

\section{Subjects}

Sixteen healthy Japanese males (age 22.4 (SD 3.2) years; weight 79.4 (SD 19.4) kg; height 1.761 (SD 0.067) m; body fat 19.2 (SD 7.5) \%) were asked to maintain their usual diet but to abstain from alcohol, caffeine and smoking $24 \mathrm{~h}$ before the investigation. The written consent of each subject was obtained before their admission to the study conducted in conformity with the Declaration of Helsinki.

\section{Spiciness and sympathetic nervous system activity}

A preliminary test was used to define a moderate and a strong dose of red pepper. In the morning, the subjects ingested a standardised breakfast $(1331 \mathrm{~kJ}(318 \mathrm{kcal})$ composed of 15,10 and $75 \%$ energy from protein, fat and carbohydrate, respectively). After $3 \mathrm{~h}$ the subjects ingested $30 \mathrm{ml}$ of consommé soups containing increasing amounts of red pepper $(0.08,0.16,0.31,0.63,1.25,2.5,5,10,20$ and $40 \mathrm{~g} / \mathrm{l}$ ). The soups were warmed to $52^{\circ} \mathrm{C}$ because capsaicin is insoluble in cold water. Between each soup tested, the subjects rinsed their mouths with water to remove any spicy taste. At $15 \mathrm{~s}$ after the ingestion of each sample of soup, the subjects were asked 'How much spiciness do you feel?', and had to choose one of the eight following answers: (1) no spiciness at all; (2) very light spiciness; (3) light spiciness; (4) moderate spiciness; (5) a little spicy; (6) spicy; (7) very spicy; (8) too spicy. The subjects did not assess the following dose of red pepper when they had rated a soup at level 8 . The moderate and maximal tolerable concentrations of red pepper were defined in the preliminary test by levels 4 and 7 of spiciness, respectively.

Immediately after the questions, heart-rate power spectra were assessed for $5 \mathrm{~min}$ with heart rate variability analysis software (MemCalc/Tarawa; GMS Co. Ltd., Tokyo, Japan), and blood pressure was measured (TM-2650; A \& D Co. Ltd., Tokyo, Japan). The electrocardiographic signals for the heart rate power spectral analysis were digitised and stored on hard disk. Power spectra were calculated from a consecutive series of R-R intervals every other $10 \mathrm{~s}$. The low frequency $(0 \cdot 04-0.15 \mathrm{~Hz} \mathrm{Eq})$ :high frequency $(0 \cdot 15-0 \cdot 50 \mathrm{~Hz} \mathrm{Eq})$ ratio (LF:HF) in the spectra was used as an indicator of the SNS:parasympathetic nervous system activity ratio as described previously (Pomeranz et al. 1985; Arai et al. 1989). Previous studies have shown the sensitivity of LF:HF with the incremental passive head-up tilt test $(r 0.75, P<0.001$; Hirayanagi et al. 1999), its reproducibility (CV 8.3\%; Ziegler et al. 1999), and its significant correlation with plasma noradrenaline ( $r$ 0.60, $P<0 \cdot 005$; Paolisso et al. 1997).

\section{Food intake}

The subjects who had participated in the preliminary experiment were randomly assigned to four experimental conditions. These were: a placebo soup plus placebo capsules $(\mathrm{PS}+\mathrm{P})$; a soup containing a moderate dose of red pepper $(0.064($ SD 0.046) g) plus placebo capsules $(\mathrm{MS}+\mathrm{P})$; a soup containing a strong dose of red pepper $(0.923(\mathrm{SD} 1.377) \mathrm{g})$ plus placebo capsules $(\mathrm{SS}+\mathrm{P})$; a placebo soup plus capsules delivering a strong dose of red pepper $(0.923($ SD 1.377) g; PS+S). On the day of the experiment, the subjects ingested a breakfast as described earlier. At $3 \mathrm{~h}$ later they consumed $150 \mathrm{ml}$ of the soup $\left(52^{\circ} \mathrm{C}\right)$ plus capsules with $80 \mathrm{ml}$ of room-temperature water. After $10 \mathrm{~min}$, food (Appendix 1) was presented to the subjects, who were instructed to eat until satiated. All subjects finished eating within $30 \mathrm{~min}$ for each experimental condition. All food given to the subjects was weighed before and after the meal to assess quantity of the ingestion.

The environmental conditions and the physical state of food affect spontaneous energy intake in human subjects (Kissileff, 1985; Himaya \& Louis-Sylvestre, 1998). In the present study, conditions of light and noise, the interval of time between meals and instructions were similar for all subjects, and the food used was habitual to them. In addition, the soups were ingested through a straw from cups that were covered in order to avoid the stimulation of sight.

\section{Statistical analysis}

Data on energy and macronutrient intake, blood pressure, and heart rate and variability were analysed by one-way ANOVA with repeated measurements (red pepper dose). A contrast analysis adjusted for multiple comparisons was used when the ANOVA revealed a significant effect or a statistical tendency. Pearson's correlation coefficient was calculated between energy and fat intakes, and between the amount of red pepper ingested and the difference in energy intake (MS+ $\mathrm{P}$ minus $\mathrm{PS}+\mathrm{P}$, and $\mathrm{SS}+\mathrm{P}$ minus $\mathrm{PS}+\mathrm{P})$. Differences were considered to be statistically significant at $P<0 \cdot 05$. All calculations were done with SuperAnova software (SAS Institute Inc., Cary, NC, USA).

\section{Results}

In the preliminary test, the subjects considered that the spiciness of red pepper was very light (level 2) and excessive (level 8) at $0 \cdot 10(\mathrm{SD} 0.07)$ and $14.14(\mathrm{SD} 10 \cdot 21) \mathrm{g} / \mathrm{l}$, respectively. There was a large variability in the evaluation of 
level 8 (range $1 \cdot 25-20 \mathrm{~g} / \mathrm{l}$ ). The moderate (level 4) and maximum tolerable concentrations (level 7) of red pepper were $0.43(\mathrm{SD} 0.31)$ and $6.15(\mathrm{SD} 9.18) \mathrm{g} / \mathrm{l}$, respectively. Since the concentrations of red pepper were similar in the test $(30 \mathrm{ml})$ and experimental $(150 \mathrm{ml})$ soups, the latter contained a total amount of 0.064(SD 0.046) and $0.923($ SD 1.377) $g$ red pepper for the $\mathrm{MS}+\mathrm{P}$ and $\mathrm{SS}+\mathrm{P}$ conditions, respectively. Medians of red pepper contents for the $\mathrm{MS}+\mathrm{P}$ and $\mathrm{SS}+\mathrm{P}$ conditions were 0.047 (25-75 percentile $0.031-0.094)$ and $0.750 \quad(25-75$ percentile $0 \cdot 375-0.750) \mathrm{g}$, respectively.

Heart rate variability (LF:HF) was significantly lower at level 8 than at level 4 and level $7(P<0 \cdot 05$; Fig. 1). Compared with the absence of spiciness, LF:HF tended to be decreased at level $8(P=0.096)$ but increased at levels $4(P=0 \cdot 100)$ and $7(P=0.073)$. There was no effect of the red pepper $(0,0.08,0.16,0.31,0.63$ and $1.25 \mathrm{~g} / \mathrm{l})$ on LF:HF, heart rate and blood pressure.

Table 1 shows the effect of red pepper on food, energy and macronutrient intake. Food, protein and carbohydrate intakes were similar in all conditions, and the moderate dose of red pepper had no effect on fat and energy intakes. However, compared with the PS $+\mathrm{P}$ condition, fat intake was significantly lower in the $\mathrm{SS}+\mathrm{P}$ condition $(-15.5 \%$; $P=0.043)$ and tended to be decreased in the PS $+\mathrm{S}$ condition $(-13.3 \% ; P=0.080)$. Moreover, energy intake tended to be lower in the SS+P $(-8.1 \% ; P=0.089)$ and the PS $+\mathrm{S}(-8.5 \% ; P=0.076)$ compared with the PS $+\mathrm{P}$ condition. On an individual basis, nine subjects increased and seven subjects decreased both their energy and fat intakes in the MS+P condition, and three subjects increased and thirteen subjects decreased their energy and fat intakes in the $\mathrm{SS}+\mathrm{P}$ condition. Energy intake was positively correlated with fat intake $(r$ 0.901, $P=0.0001 ; n$ 48). Change in energy intake was negatively correlated with the amount of red pepper ingested $(r 0.42$, $P=0.02 ; n$ 32).

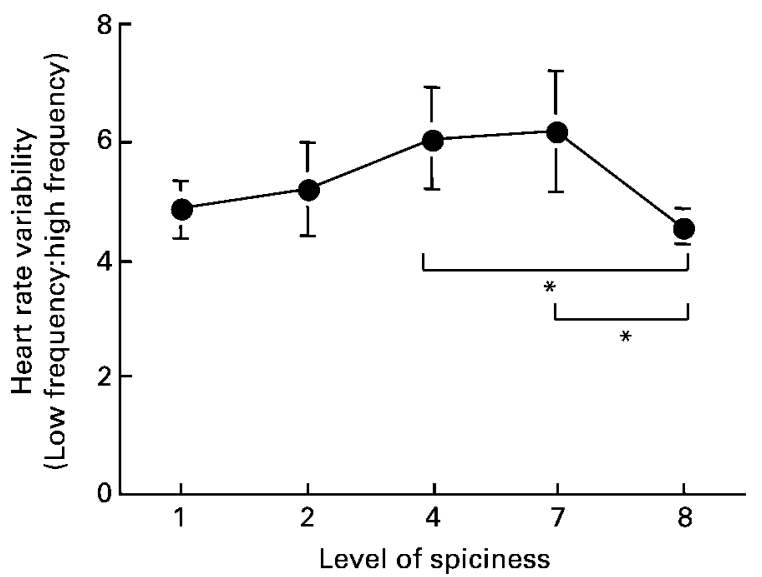

Fig. 1. Heart rate variability (low frequency:high frequency) as a measure of the sympathetic:parasympathetic nervous system activity ratio (for details, see p. 992) plotted against rated spiciness of red pepper soup. Values are means, with standard errors of the mean represented by vertical bars. * Mean value was significantly lower at level 8 than at level 4 and level $7(P<0 \cdot 05)$.

\section{Discussion}

The aim of the present study was to investigate the effect of red pepper on energy and macronutrient intakes in young healthy Japanese males. Preliminary test soups were used to determine a moderate and the maximal tolerable dose of red pepper, and to assess the doseresponse of the SNS. The subjects ingested a placebo, a moderate or a maximal tolerable dose of red pepper in a soup at the beginning of a meal. In order to assess the role of the mouth in the effect of red pepper, all subjects were also evaluated in another experimental condition in which the maximal dose was given in capsules with a placebo soup. Ad libitum food intake was analysed at the end of the meals. Red pepper lowered subsequent energy intake in a dose-dependent manner. Moreover, the maximal tolerable dose of red pepper in the soup suppressed fat intake compared with the placebo. Although this effect was not accompanied by a decrease in total energy intake due to the large variability between the subjects, energy intake was positively correlated with fat intake.

The red pepper used in the present study is composed of about $0.3 \%$ capsaicin (or 55000 Scoville heat units), its pungent principal (Iwai \& Watanabe, 2000). The subjects detected the spiciness of the test soup at $0 \cdot 10$ (SD 0.07) $\mathrm{g}$ red pepper $/ \mathrm{l}$, or $0.3 \mu \mathrm{g}$ capsaicin $/ \mathrm{ml}$, and considered it very spicy or too spicy at concentrations 60- and 140fold higher respectively. The present results are similar to those of previous studies in which $0 \cdot 1-1.0 \mu \mathrm{g} / \mathrm{ml}$ was the minimal concentration of capsaicin felt by the human tongue, and hot to burning sensations began at $10-100 \mu \mathrm{g} / \mathrm{ml}$ (Craft \& Porreca, 1992).

There was a biphasic effect of red pepper on SNS activity assessed by LF:HF. The moderate and maximal tolerable concentrations evoked the highest levels of SNS activity, which was significantly lowered by the strongest dose, identified as 'too spicy' by the subjects. Capsaicin is known to stimulate SNS activity but this effect was suppressed by contact of the tongue with a very high dose (Craft \& Porreca, 1992) or capsaicin pre-treatment (Watanabe et al. 1991). Therefore, the SNS response appeared to be blunted, since the highest dose of red pepper in the test soup induced desensitisation of capsaicin-sensitive neurons. We did not evaluate the effect of red pepper on food intake at a dose that was painful for the subjects and had little acceptability.

It has previously been reported that red pepper decreases fat intake in Japanese women and carbohydrate intake in male Caucasians (Yoshioka et al. 1995, 1998, 1999). Along with the original findings of the present study, these results suggest that both male and female Japanese respond similarly to red pepper by a decrease in fat intake; this is different from Caucasians. The reason for these divergences is unclear. It is noteworthy that the average Japanese diet is low in fat compared with that of Caucasians. Therefore, it may be that this apparent macronutrient-specific anorexic effect of red pepper is modulated by the usual diet composition. Moreover, our previous studies suggested that red pepper decreases energy intake by stimulating the SNS (Yoshioka et al. 1995, 1998, 1999). In the present 
Table 1. Energy and macronutrient intake after the ingestion of red pepper soup* (Mean values and standard deviations)

\begin{tabular}{|c|c|c|c|c|c|c|c|c|}
\hline & \multicolumn{2}{|c|}{$P S+P$} & \multicolumn{2}{|c|}{$\mathrm{MS}+\mathrm{P}$} & \multicolumn{2}{|c|}{$S S+P$} & \multicolumn{2}{|c|}{$P S+S$} \\
\hline & Mean & SD & Mean & SD & Mean & SD & Mean & SD \\
\hline Food intake (g) & 1216 & 401 & 1216 & 416 & 1193 & 434 & 1170 & 331 \\
\hline Energy intake (kJ) & 6326 & 2406 & 6226 & 2264 & 5812 & 2234 & 5786 & 1900 \\
\hline Protein intake (g) & 54.0 & $19 \cdot 3$ & $54 \cdot 2$ & $21 \cdot 1$ & $49 \cdot 7$ & $18 \cdot 6$ & $52 \cdot 0$ & $16 \cdot 1$ \\
\hline Fat intake $(\mathrm{g})$ & $60 \cdot 1^{\mathrm{a}}$ & $29 \cdot 2$ & $58 \cdot 9^{\mathrm{ab}}$ & $23 \cdot 1$ & $50 \cdot 8^{\mathrm{b}}$ & 21.5 & $52 \cdot 1^{\mathrm{ab}}$ & $19 \cdot 4$ \\
\hline Carbohydrate intake (g) & $188 \cdot 8$ & $70 \cdot 0$ & $185 \cdot 7$ & $77 \cdot 2$ & 183.2 & 81.5 & $176 \cdot 6$ & $60 \cdot 5$ \\
\hline
\end{tabular}

$\mathrm{PS}+\mathrm{P}$, placebo soup plus placebo capsules; MS+P, moderate soup plus placebo capsules; $S \mathrm{~S}+\mathrm{P}$, strong soup plus placebo capsules; $\mathrm{PS}+\mathrm{S}$, placebo soup plus strong capsules.

${ }^{a, b}$ Mean values within a row with unlike superscript letters were significantly different $(P<0.05)$.

${ }^{*}$ For details of subjects and procedures, see p. 992.

study, at doses that do not induce desensitisation of neurons, the amount of red pepper ingested was negatively correlated with energy intake, suggesting a use of red pepper as a successful prescription to reduce subsequent ad libitum energy intake. However, in contrast to what is found in healthy Japanese, the stimulation of SNS activity by capsaicin is blunted in Japanese obese individuals (Matsumoto et al. 2000). This abnormal response could involve the TEF, especially the cephalic phase, which is normally stimulated by red pepper (Yoshioka et al. 1995, 1998; Lim et al. 1997). Further studies related to red pepper and food intake in overweight, obese and post-obese individuals will be required.

In the present study, the absence of significant effects with the red pepper administered in capsules should be interpreted with caution because of the large variability in the response between subjects. Fat intake was decreased by $13.3 \%$ with the strong capsules compared with the placebo condition $(P=0.08)$ but was very similar to the strong soup condition $(P=0.77)$. Consequently, we suggest that the effects of red pepper on energy and macronutrient intake do not occur in the mouth. A similar mechanism could also be involved in the effect of another anorexic product, $\mathrm{CH}-19$ sweet, the non-pungent cultivar of red pepper (Kobata et al. 1999). Indeed, $\mathrm{CH}-19$ sweet has been found to increase $\mathrm{O}_{2}$ consumption and body temperature in human subjects (Ohnuki et al. 2001a). Also, capsiate, which is found in $\mathrm{CH}-19$ sweet, reduces body fat accumulation in a dosedependent manner in mice by increasing $\mathrm{O}_{2}$ consumption (Ohnuki et al. 2001b) and body temperature (Ohnuki et al. 2001c). For individuals who dislike the pungency of red pepper, $\mathrm{CH}-19$ sweet might be a potential surrogate in trials to prevent weight gain in susceptible individuals.

In summary, soups containing red pepper induced a dose-dependent decrease in subsequent energy intake, and the dose responsible for the maximal tolerable feeling of spiciness reduced fat intake in Japanese males. It is suggested that the effect of red pepper on food intake behaviour occurs after passing through the mouth and involves activation of the SNS. The present study raises the interesting possibility that red pepper could be useful in the prevention of the development of obesity.

\section{Acknowledgements}

The authors thank Dr Yoshito Mukaino for the heart-rate power spectral analysis.

\section{References}

Arai Y, Saul P, Albrecht P, Hartley LH, Lilly LS, Cohen RJ \& Colucci WS (1989) Modulation of cardiac autonomic activity during and immediately after exercise. Am J Physiol 256, H132-H141.

Bennett C, Reed GW, Peters JC, Abumrad NN, Sun M \& Hill JO (1992) Short-term effects of dietary-fat ingestion on energy expenditure and nutrient balance. Am J Clin Nutr 55, 1071-1077.

Craft RM \& Porreca F (1992) Treatment parameters of desensitization to capsaicin. Life Sci 51, 1767-1775.

Diamond P, Brondel L \& LeBlanc J (1985) Palatability and postprandial thermogenesis in dogs. Am $J$ Physiol 248, E75-E79.

Doucet E \& Tremblay A (1997) Food intake, energy balance and body weight control. Eur J Clin Nutr 51, 846-855.

Dulloo AG (1998) Spicing fat for combustion. Br J Nutr 80, 493-494.

Flatt JP, Ravussin E, Acheson KJ \& Jéquier E (1985) Effects of dietary fat on postprandial substrate oxidation and on carbohydrate and fat balances. J Clin Invest 76, 1019-1024.

Himaya A \& Louis-Sylvestre J (1998) The effect of soup on satiation. Appetite 30, 199-210.

Hirayanagi K, Iwasaki K, Sasaki T, Kinugasa H, Miyamoto A \& Yajima K (1999) Sensitivity analyses of heart rate variability variables by an incremental, passive head-up tilt. Uchu Koku Kankyo Igaku 36, 67-74.

Iwai K \& Watanabe A (2000) Red Peppers: Science of Pungency. Tokyo: Saiwai Syobo.

Kendall A, Levitsky DA, Strupp BJ \& Lissner L (1991) Weight loss on a low-fat diet: consequence of the imprecision of the control of food intake in humans. Am J Clin Nutr 53, $1124-1129$.

Kissileff HR (1985) Effects of physical state (liquid-solid) of foods on food intake: procedural and substantive contributions. Am J Clin Nutr 42, 956-965.

Kobata K, Sutoh K, Todo T, Yazawa S, Iwai K \& Watanabe T (1999) Nordihydrocapsiate, a new capsinoid from the fruits of a nonpungent pepper, capsicum annuum. J Nat Prod 62, $335-336$.

Lim K, Yoshioka M, Kikuzato S, Kiyonaga A, Tanaka H, Shindo M \& Suzuki M (1997) Dietary red pepper ingestion increased carbohydrate oxidation at rest and during exercise in runners. Med Sci Sports Exerc 29, 355-361. 
Lissner L, Levitsky DA, Strupp BJ, Kalkwarf HJ \& Roe DA (1987) Dietary fat and the regulation of energy intake in human subjects. Am J Clin Nutr 46, 886-892.

Matsumoto T, Miyawaki C, Ue H, Yuasa T, Miyatsuji A \& Moritani T (2000) Effects of capsaicin-containing yellow curry sauce on sympathetic nervous system activity and dietinduced thermogenesis in lean and obese young women. J Nutr Sci Vitaminol (Tokyo) 46, 309-315.

Ohnuki K, Niwa S, Maeda S, Inoue N, Yazawa S \& Fushiki T (2001a) CH-19 sweet, a non-pungent cultivar of red pepper, increased body temperature and oxygen consumption in humans. Biosci Biotechnol Biochem 65, 2033-2036.

Ohnuki K, Haramizu S, Oki K, Watanabe T, Yazawa S \& Fushiki T (2001b) Administration of capsiate, a non-pungent capsaicin analog, promotes energy metabolism and suppresses body fat accumulation in mice. Biosci Biotechnol Biochem 65, 2735-2740.

Ohnuki K, Haramizu S, Watanabe T, Yazawa S \& Fushiki T (2001c) $\mathrm{CH}-19$ sweet, nonpungent cultivar of red pepper, increased body temperature in mice with vanilloid receptors stimulation by capsiate. J Nutr Sci Vitaminol (Tokyo) 47, 295-298.

Paolisso G, Manzella D, Ferrara N, et al. (1997) Glucose ingestion affects cardiac ANS in healthy subjects with different amounts of body fat. Am J Physiol 273, E471-E478.

Pomeranz B, Macaulay RJ, Caudill MA, Kutz I, Adam D, Gordon D, Kilborn KM, Barger AC, Shannon DC, Cohen RJ \& Benson H (1985) Assessment of autonomic function in humans by heart rate spectral analysis. Am J Physiol 248, H151-H153.

Rothwell NJ \& Stock MJ (1978) A paradox in the control of energy intake in the rat. Nature 273, 146-147.

Schutz Y, Flatt JP \& Jéquier E (1989) Failure of dietary fat intake to promote fat oxidation: a factor favoring the development of obesity. Am J Clin Nutr 50, 307-314.
Taubes G (1998) As obesity rates rise, experts struggle to explain why. Science 280, 1367-1368.

Thomas CD, Peters JC, Reed GW, Abumrad NN, Sun M \& Hill JO (1992) Nutrient balance and energy expenditure during ad libitum feeding of high-fat and high-carbohydrate diets in humans. Am J Clin Nutr 55, 934-942.

Warwick ZS \& Schiffman SS (1992) Role of dietary fat in calorie intake and weight gain. Neurosci Biobehav Rev 16, 585-596.

Watanabe A, Kawada T, Kurosawa M, Sato A \& Iwai K (1991) Thermogenic action of capsaicin and its analogs. In Obesity: Dietary Factors and Control, pp. 67-77 [M Suzuki, editor]. Tokyo and Basel: Japan Scientific Societies Press and S Karger AG.

Wickelgren I (1998) Obesity: how big a problem? Science 280, $1364-1367$.

Yoshioka M, Doucet E, Drapeau V, Dionne I \& Tremblay A (2001) Combined effects of red pepper and caffeine consumption on 24-h energy balance in subjects given free access to foods. Br J Nutr 85, 203-211.

Yoshioka M, Lim K, Kikuzato S, Kiyonaga A, Tanaka H, Shindo M \& Suzuki M (1995) Effects of red-pepper diet on the energy metabolism in men. J Nutr Sci Vitaminol (Tokyo) 41, 647-656.

Yoshioka M, St-Pierre S, Drapeau V, Dionne I, Doucet E, Suzuki M \& Tremblay A (1999) Effect of red pepper on appetite and energy intake. Br J Nutr 82, 115-123.

Yoshioka M, St-Pierre S, Suzuki M \& Tremblay A (1998) Effect of red pepper added to high-fat and high-carbohydrate meals on energy metabolism and substrate utilization in Japanese women. Br J Nutr 80, 503-510.

Ziegler D, Piolot R, Strassburger K, Lambeck H \& Dannehl K (1999) Normal ranges and reproducibility of statistical, geometric, frequency domain, and non-linear measures of 24-hour heart rate variability. Horm Metab Res 31, $672-679$.

Appendix 1. List of food served (and the amount of food) during the lunchtime buffet

\begin{tabular}{|c|c|c|}
\hline Milk, $2 \%$ fat $(500 \mathrm{ml})$ & Croissants (100 g) & Chocolate cookies (55 g) \\
\hline Milk, $3.6 \%$ fat $(500 \mathrm{ml})$ & White bread (140 g) & Okaki (rice cookies) (55 g) \\
\hline Fruit yoghurt $(75 \mathrm{~g})$ & White rice $(200 \mathrm{~g})$ & Potato crisps (35 g) \\
\hline Sliced cheese $(40 \mathrm{~g})$ & Cucumber $(60 \mathrm{~g})$ & Barley tea $(350 \mathrm{ml})$ \\
\hline Grilled fish $(260 \mathrm{~g})$ & Lettuce $(50 \mathrm{~g})$ & Cola $(350 \mathrm{ml})$ \\
\hline Non-oil tuna $(90 \mathrm{~g})$ & Tomatoes $(70 \mathrm{~g})$ & Sprite (350 ml) \\
\hline Hamburger steak (260 g) & Umeboshi (pickles) (45g) & Butter $(20 \mathrm{~g})$ \\
\hline Salami $(45 \mathrm{~g})$ & Bananas $(120 \mathrm{~g})$ & Strawberry jam $(40 \mathrm{~g})$ \\
\hline Sliced ham (50 g) & Oranges (120 g) & Frikake (seasoned powder) $(15 \mathrm{~g})$ \\
\hline & Orange juice $(300 \mathrm{ml})$ & Ketchup $(50 \mathrm{~g})$ \\
\hline & Ajitsuke nori (seaweed) (15 g) & Soya sauce $(130 \mathrm{~g})$ \\
\hline & Wakame (seaweed) (15 g) & Mayonnaise (150 g) \\
\hline & & French dressing $(30 \mathrm{~g})$ \\
\hline & & Non-oil dressing (30 g) \\
\hline
\end{tabular}

